\title{
Carotenoids: functions and fallacies
}

\author{
B Y DAVID I. THURNHAM \\ Human Nutrition Research Group, Department of Biology and Biomedical Sciences, \\ University of Ulster, Coleraine BT52 ISA, Northern Ireland
}

Many epidemiological studies have demonstrated an association between a high intake of fruits and vegetables and a low risk of diseases, particularly epithelial cancers (Hennekens, 1986). Initially these foods were considered only as a source of retinol, that is vitamin A, since vitamin A-deficient diets have been linked with cancer for almost 60 years (for review, see Moon, 1989). Furthermore, retinoids (compounds with a chemical structure based on that of retinol) are well-established chemoprotective agents for experimental carcinogenesis. In 1981, however, Peto et al. (1981) questioned the assumption that vitamin $\mathrm{A}$ was the protective ingredient in plant material. Their main argument was that most people in the Western World had satisfactory vitamin A status and feeding more vitamin $\mathrm{A}$ whether in the form of plant material or preformed retinol itself had very little, if any, effect on circulating vitamin A levels since the amount in blood is endogenously regulated. The authors pointed out, however, that provitamin A, that is $\beta$-carotene, was not similarly controlled. Circulating levels of $\beta$-carotene were influenced by the dietary intake of plant foods and, therefore, $\beta$-carotene might be the cancer-preventive ingredient.

The reader will be forgiven for thinking that the only carotenoid of any importance is $\beta$-carotene. Most nutritionists were weaned onto the subject of nutrition on the understanding that the only carotenoid of any importance is $\beta$-carotene. Indeed, $\beta$-carotene is the major source of vitamin A for the majority of the world's population and although there may be fifty or so provitamin A carotenoids (Olson, 1989), none of them is as effective or as important as $\beta$-carotene as a source of vitamin $A$.

The purpose of the present review is to discuss some of the other functions of carotenoids and I hope to dispel some of the fallacies. In any discussion of function one must consider the nature of the molecule and its localization within tissues and cells in relation to possible physiological action. The carotenoids are compounds which, although similar in structure, may well have quite different activities at the cellular level. Therefore, it is important to know which carotenoids are found in man and what specific properties these may have in relation to those functions which might be important.

\section{STRUCTURE OF CAROTENOIDS}

Approximately 600 naturally occurring carotenoids have been characterized. Most have forty $\mathrm{C}$ atoms and most of them, known as xanthophylls, are oxygenated. Less than $10 \%$ of them are hydrocarbons.

There are five well-characterized carotenoids (Fig. 1) in most blood samples (Bieri et al. 1985; Thurnham \& Flora, 1988; Cantilena et al. 1992) and others, particularly xanthophylls, that have not yet been identified (Thompson et al. 1985). $\beta$-Carotene comprises $10-15 \%$ of the total. It is a symmetrical molecule in which two $\beta$-ionone rings are separated by a $\mathrm{C}_{22}$ central unit containing nine conjugated double bonds and four 


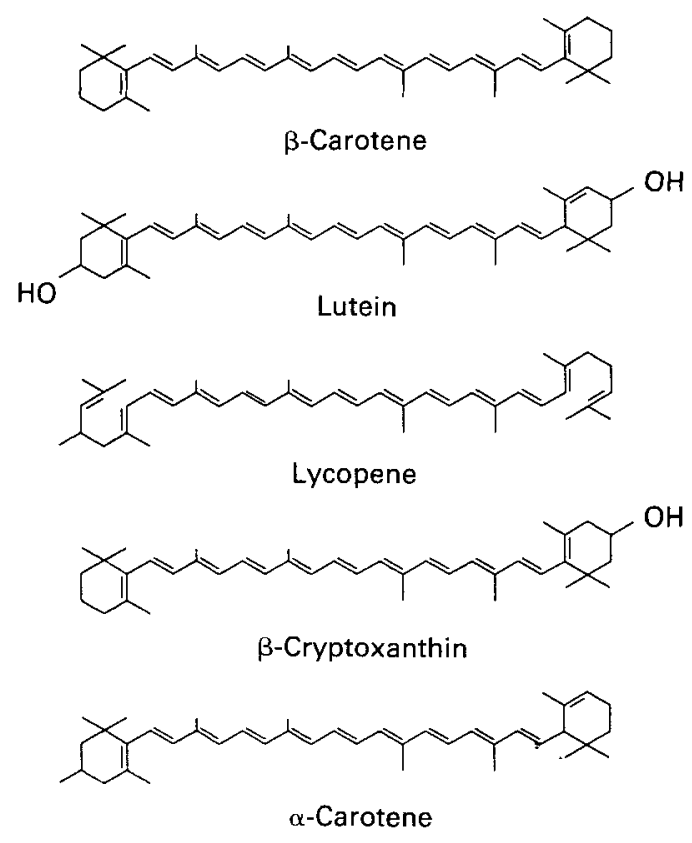

Fig. 1. Structures of the principal identified carotenoids in human blood in order of descending concentrations.

side-chain methyl groups. $\alpha$-Carotene differs from $\beta$-carotene in the position of one double bond in one ring; it is a minor but regular component. The 4,4'-dihydroxylated xanthophyll derivatives of these carotenes are lutein and zeaxanthin respectively. Lutein comprises between 10 and $40 \%$ of total carotenoids while zeaxanthin is a relatively minor component except in people for whom yellow maize is a staple food. Lycopene, the red pigment found in tomatoes, is a hydrocarbon but lacks the terminal ring structures of the carotenes. It is also a major component in blood in Western countries. $\beta$-Cryptoxanthin is a monohydroxylated form of $\beta$-carotene and the main dietary source is oranges. There is very little evidence of diurnal changes in plasma carotenoids and, in spite of the relationship between dietary intake and plasma concentrations, no seasonal changes have been found either in America (Cantilena et al. 1992) or Britain except for $\beta$-cryptoxanthin (Thurnham \& Flora, 1988) which is higher in the early part of the year.

\section{DISTRIBUTION OF CAROTENOIDS WITHIN THE TISSUE}

Carotenoids have been determined in a variety of human tissues but the only tissue where specific carotenoids appear to be located is the eye. Handelman and colleagues reported that zeaxanthin is localized in macular pigment and lutein is dispersed throughout the entire retina in humans (Handelman et al. 1988) and primate species (Handelman et al. 1991). It is still not clear whether the function of these carotenoids is protective against illumination or to act as filters for specific wave bands.

Carotenoids are also found in other tissues including skin (Culling-Berglund et al. 
1989), erythrocyte membranes (Mathews-Roth, 1975), leucocytes (Mathews-Roth, 1978), buccal mucosa (Stich et al. 1984; Cooney et al. 1991), adipose (Parker, 1988) and a variety of other tissues at autopsy (Kaplan et al. 1990; Schmitz et al. 1991). Enormous variations in concentrations were noted between different organs and while some workers report the only consistency in their findings was a qualitatively similar pattern of carotenoids in serum and different tissues (Kaplan et al. 1990), others suggest variability may be related to state of health (Schmitz et al. 1991). The latter workers suggested that liver contained high concentrations of carotenoids, compared with lung and kidney, and the predominant carotenoid was either $\beta$-carotene or lycopene. These tissue levels reflect American dietary patterns and may be different elsewhere but no reports on tissue concentrations in other countries have yet been published.

\section{FUNCTIONS OF CAROTENOIDS}

There are two well-established functions of carotenoids in man. The first is that compounds containing the $\beta$-ionone ring are potential sources of vitamin $A$, and the second is a therapeutic role which $\beta$-carotene has been shown to have in patients with erythropoietic protoporphyria and is linked to the number of conjugated double bonds in the molecule.

In addition, experimental and epidemiological evidence suggests that carotenoids may be protective against cancer, particularly lung cancer, and heart disease.

\section{Synthesis of vitamin $A$}

There are two possible mechanisms by which carotenes are converted to vitamin $\mathrm{A}$; central or excentric cleavage. $\beta$-Carotene is stoichiometrically equivalent to two molecules of retinol and the product of central cleavage of $\beta$-carotene would be two mole equivalents of retinal. Cleavage of $\beta$-carotene excentrically produces several $\beta$-apocarotenals of different chain lengths $\left(12^{\prime}-, 10^{\prime}-, 8^{\prime}-\right)$ and this is less efficient than central cleavage. Numerous in vivo studies have shown that the efficiency of $\beta$-carotene conversion to retinol is low and in many studies is only $40-60 \%$. The $\beta$-carotene- $15,15^{\prime}-$ dioxygenase ( $E C$ 1.13.11.21) is capable of cleaving both $\beta$-carotene and $\beta$-apo-carotenals to produce vitamin A but very little of the $\beta$-apo-carotenals have been detected, although the in vitro activity of the cleavage enzyme can be quite high. In the rabbit gut the activity of the enzyme is approximately 200 -fold greater than that required to meet nutritional needs (for review, see Olson, 1989). Recently, however, Wang et al. (1991) found significant amounts of $\beta$-apo-carotenals after incubation of $\beta$-carotene with intestinal homogenates from four species, including man. In addition, reported rates of formation of the apo-carotenals were 7-14-fold greater than that of retinal suggesting that excentric cleavage may be the more physiologically important mechanism.

\section{Photoprotective properties of $\beta$-carotene}

Carotenoids are well known to protect plant cells from light, $\mathrm{O}_{2}$ and photosensitivity but it was Foote \& Denny (1968) who were first to explain why carotenoids had photoprotective properties when they demonstrated that carotenoids could quench excited singlet $O$. The maximum quenching effect was obtained from pigments having nine or more 
conjugated double bonds. Strictly speaking it is not an oxidative process but a transfer of excitation energy. Carotenoids interact with singlet $O$ to give a triplet state carotenoid and ground state $O$ and the excitation energy within the molecule is dissipated as heat. This mechanism protects plant chlorophyll from oxidative damage and may also be relevant to the function of $\beta$-carotene in the treatment of certain skin diseases with carotenoids. Mathews-Roth et al. (1974) showed that erythropoietic protoporphyria responds to $\beta$-carotene therapy and, in addition, that the response was only a feature of carotenoids with nine or more conjugated bonds.

The use of $\beta$-carotene therapy in patients with erythropoietic protoporphyria has been shown to be highly effective but the doses required are often in excess of $180 \mathrm{mg} / \mathrm{d}$ and clearly indicate a pharmacological effect (Mathews-Roth et al. 1977). $\beta$-Carotene in excess of $15 \mathrm{mg} / \mathrm{d}$ will cause carotenodermia in most people but evidence for a protective effect of carotenes against solar irradiation in persons without skin disease has been lacking. It was recently shown, however, that doses of $\beta$-carotene bordering on the physiological $(30 \mathrm{mg} / \mathrm{d}$ ) were effective in lowering erythema, delaying the erythemal response and accelerating recovery times in young women exposed to intense solar radiation over $12 \mathrm{~d}$ (Gollnick et al. 1993). Whether an intake of $30 \mathrm{mg} \beta$-carotene/d can ever be regarded as moderate as the authors suggest, when the average intake in Western countries is $2 \mathrm{mg}$ (Gregory et al. 1990), is questionable.

Other work has also shown that $\beta$-carotene $(50 \mathrm{mg} / \mathrm{d})$ did not protect against skin cancer when administered over 5 years in a randomized double-blind trial to high-risk subjects who had a recent non-melanoma skin cancer before starting in the trial (Greenberg et al. 1990).

\section{Carotenes and cardiovascular disease}

Diets rich in fruit and vegetables are generally associated with a lower risk of cardiovascular disease but evidence that $\beta$-carotene directly may give protection against vascular disease has recently been reported from the Physicians Health Study in America (Gaziano et al. 1990). In an analysis on a subgroup of participants who had previously had a cardiovascular event (stable angina or coronary revascularization), those on $\beta$-carotene ( $50 \mathrm{mg}$ every other day) experienced almost $50 \%$ fewer subsequent events than those receiving the placebo (Gaziano et al. 1990).

Free-radical damage is implicated in the aetiology of cardiovascular disease. Oxidized LDL is avidly scavenged by macrophages and the latter may subsequently convert to foam cells in the arterial intima where they form fatty streaks and later atherosclerotic plaques (Esterbauer et al. 1990). Furthermore, in vitro susceptibility of LDL to oxidation has been shown to correlate with clinical severity in persons recently having a heart attack (Regnstrom et al. 1992).

Antioxidants such as Probucol have been shown to be important experimentally in preventing atherosclerotic lesions (Carew et al. 1987) but the relative importance of the factors determining lipoprotein oxidizability are not known. Vitamin $E$ is the predominant antioxidant in lipoproteins but in unsupplemented population studies there is no correlation between vitamin E levels and LDL susceptibility to oxidation (DieberRotheneder et al. 1991). Oxidative resistance, therefore, probably depends on the combined oxidative defences within the LDL particle which include carotenoids, ubiquinol and other antioxidants. 
Table 1. Correlations between cholesterol and fat-soluble micronutrients in plasma $\dagger$

\begin{tabular}{lcc}
\hline \hline & \multicolumn{2}{c}{$\begin{array}{c}\text { Partial correlation coefficients } \\
\text { with cholesterol }\end{array}$} \\
\cline { 2 - 3 } & Momen $(n 459)$ & Men $(n$ 455) \\
\hline Micronutrient & $0.48^{*}$ & $0.61^{*}$ \\
Lutein & $0.30^{*}$ & $0.27^{*}$ \\
$\beta$-Cryptoxanthin & 0.14 & 0.12 \\
Lycopene & 0.07 & 0.09 \\
$\alpha$-Carotene & 0.03 & 0.08 \\
$\beta$-Carotene & 0.02 & 0.02 \\
\hline
\end{tabular}

* $P<0 \cdot 01$.

$\dagger$ Data are obtained from adult British subjects surveyed during 1986-7 in England, Wales and Scotland (Gregory et al. 1990). Plasma lutein was measured only during the second half of the survey.

We have been particularly interested in lutein in lipoproteins since it would appear to be more evenly distributed within the different lipoprotein classes than the other carotenoids (Krinsky et al. 1958; Thurnham et al. 1993). In addition, plasma lutein is correlated with cholesterol, which is also a characteristic of vitamin E (Horwitt et al. 1972) but not of other plasma carotenoids (Table 1; Thurnham, 1989), and this may indicate a separate role for lutein within lipoproteins.

Currently, evidence is conflicting with respect to the role of carotenoids in lipoproteins. In the case of $\beta$-carotene, two in vitro studies reported no effect (Morel et al. 1983; van Hinsberg et al. 1986) while two others reported increased LDL resistance to oxidation in the presence of $\beta$-carotene (Jialal \& Grundy, 1991; Lavy et al. 1992). We have recently reported the in vitro incorporation of lutein within LDL and its effect on the susceptibility of LDL to oxidation. By increasing the concentration of lutein 10-fold, the lag phase following $\mathrm{Cu}$-stimulated $\mathrm{LDL}$ oxidation was more than doubled $(109 \%$; Chopra et al. 1993a). This increase in lag phase is ten times greater on a molar basis than that produced by the in vitro incorporation of vitamin $\mathrm{E}$ (137\%; Esterbauer et al. 1991) since the extra amount of vitamin $E$ incorporated into the LDL was eleven times greater than that of lutein $(8.78 \mathrm{compared}$ with $0.814 \mathrm{nmol} / \mathrm{mg}$; Table 2$)$. If a similar increase in resistance to oxidation follows the in vivo incorporation of lutein into LDL, then this could suggest that some carotenoids can exert antioxidant effects similar to those of vitamin $E$, in spite of the lower concentrations of carotenoids compared with vitamin $E$ in lipoproteins (Esterbauer et al. 1990).

Two in vivo $\beta$-carotene-feeding studies have been reported; one involving adult smokers (Princen et al. 1992) and the other in patients with cystic fibrosis (CF; Winklhofer-Roob et al. 1993). With the smokers there was a significant increase in LDL- $\beta$-carotene $(0 \cdot 22-3.66 \mathrm{nmol} / \mathrm{mg} \mathrm{LDL})$ but no increased resistance to oxidation. With the CF patients, however, LDL- $\beta$-carotene increased $(0 \cdot 008-0 \cdot 108 \mathrm{nmol} / \mathrm{mg}$ LDL) and there was a $38 \%$ increase in oxidative resistance. The difference between these studies may reflect the fact that $\mathrm{CF}$ patients had abnormally low $\beta$-carotene and low resistance of LDL to oxidation and both increased to the normal range following supplementation. With the smokers, $\beta$-carotene and susceptibility of LDL to oxidation were within the normal range at the outset. 
Táble 2. Influence of antioxidant incorporation into $L D L$ on oxidative resistance*

\begin{tabular}{|c|c|c|c|c|c|c|}
\hline & \multicolumn{3}{|c|}{ Antioxidant (nmol/mg LDL) } & \multicolumn{3}{|c|}{ Lag phase (min) } \\
\hline & $\begin{array}{c}\text { Before } \\
\text { supplemen- } \\
\text { tation }\end{array}$ & $\begin{array}{l}\text { After } \\
\text { supplemen- } \\
\text { tation }\end{array}$ & Increase & $\begin{array}{c}\text { Before } \\
\text { supplemen- } \\
\text { tation }\end{array}$ & $\begin{array}{c}\text { After } \\
\text { supplemen- } \\
\text { tation }\end{array}$ & Increase \\
\hline Vitamin $\mathrm{E}$ & $3 \cdot 27$ & $12 \cdot 15$ & 8.78 & 80 & 190 & $110(137 \%)$ \\
\hline Lutein & 0.078 & 0.982 & $0 \cdot 814$ & 104 & 217 & $113(109 \%)$ \\
\hline
\end{tabular}

* The data shown are from two publications in which $\alpha$-tocopherol $(1000 \mu \mathrm{mol} / \mathrm{l}$; Esterbauer et al. 1991) or lutein ( $50 \mu \mathrm{mol}$ lutein/l plasma; Chopra \& Thurnham, 1993) were incubated with plasma at $37^{\circ}$ for $3 \mathrm{~h}$ after which LDL were separated by ultracentrifugation. LDL were prepared by the same method (DieberRotheneder et al. 1991) in both experiments and oxidized using either $1.66 \mu$ mol $\mathrm{CuCl}_{2}$ or $\mathrm{CuSO}_{4} / \mathrm{l}$ as prooxidant respectively. Lipid peroxidation was measured continuously by measuring diene absorption at 234 $\mathrm{nm}$. Results show the $\alpha$-tocopherol and lutein concentrations in LDL prepared from blood before and after supplementation and the corresponding lag phases (min) following exposure of LDL $(0.25 \mathrm{mg} / \mathrm{ml})$ to the $\mathrm{Cu}$ salt in vitro.

\section{$\beta$-Carotene and cancer}

Epidemiologically, the most consistent evidence that carotenes may be protective against cancer is the findings from five prospective case-control studies all of which reported that low plasma $\beta$-carotene levels were associated with an elevated risk of lung cancer (see Connett et al. 1989). In addition, several intervention trials with $\beta$-carotene have shown promising results against precancerous conditions of the upper aerodigestive tract, which includes the head, neck and throat (Stich et al. 1988; Garewal \& Shamdas, 1991).

Even in healthy tissues, there is evidence that DNA may be subjected to continuous attack and damage by free radicals. DNA repair mechanisms exist for all known types of damage but some of these are relatively slow processes; thus, where there is concurrent inflammation and/or hyperplasia, replication may occur before repair is completed, and damage, which might initiate cancer, can be replicated. Thus, antioxidant properties of carotenoids may protect specific tissues by modulating free-radical activity and by reducing the level of damage (Thurnham, 1993). For example, in vitro, $\beta$-carotene will prevent increased sister chromatid exchanges and malignant transformation in cultured cells and in animal models $\beta$-carotene and canthaxanthin protect against u.v.-induced skin cancer as well as some chemically-induced cancers (for review, see Krinsky, 1991).

Two possible mechanisms are being investigated; (1) protection via the antioxidant properties of carotenoids and/or (2) a direct influence on immune function.

\section{CAROTENOIDS AS ANTIOXIDANTS}

Burton \& Ingold (1984) showed that $\beta$-carotene had unusual antioxidant properties. These workers suggested that at low $\mathrm{O}_{2}$ pressures the lipid peroxyl radical attached itself to the conjugated chain and the unpaired electron was delocalized through the chain. More recently, it has been suggested that the value for mol $\mathrm{O}_{2}$ consumed:mol initial $\beta$-carotene consumed was about 6 (Mordi, 1993). Burton \& Ingold (1984) also suggested that other carotenoids would also have antioxidant properties. This was later confirmed by Terao (1989), using a similar peroxyl radical-generating system, who reported that the 


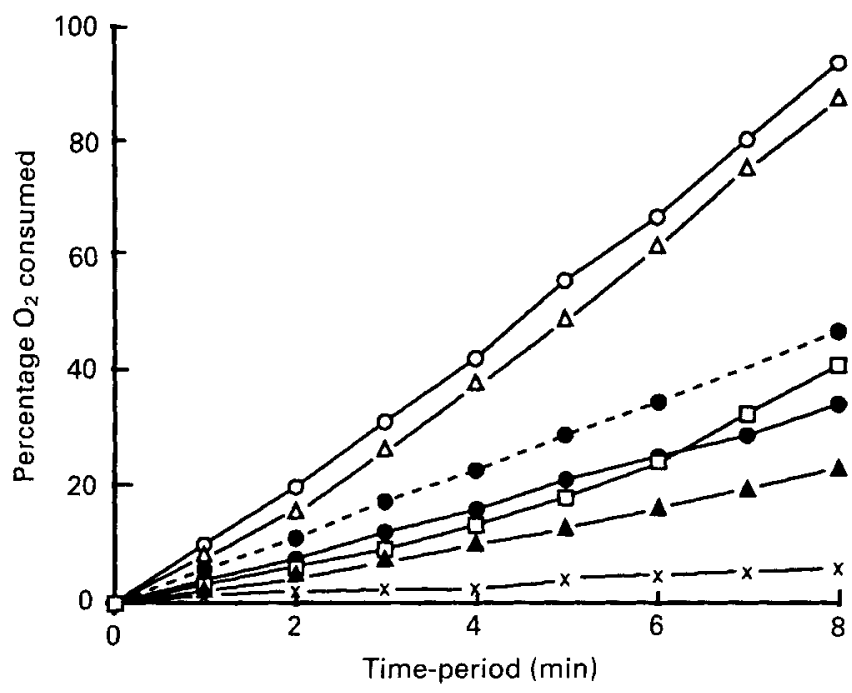

Fig. 2. Peroxyl radical-quenching properties of lutein, $\beta$-carotene and Trolox (water-soluble form of vitamin $E$ : Aldrich Biochemicals). Lipid peroxidation was initiated in a Clark $\mathrm{O}_{2}$ electrode with 133 mmol 2,2-azo-bis(2,4dimethyl) valeronitrile $(\boldsymbol{\Delta})$ or $13.3 \mathrm{mmol}$ methyl linoleic acid $(\mathrm{X}) / \mathrm{l}$ ethyl alcohol at $50^{\circ}$ or both $(\mathrm{O})$ alone or in the presence of $10 \mu \mathrm{M}$ - $\beta$-carotene $(\Delta), 10 \mu \mathrm{M}-(--)$ or $25 \mu \mathrm{M}-(-\bullet)$ lutein or Trolox $(\square)$ as shown. All concentrations shown are final ones. $\mathrm{O}_{2}$ consumption was used to monitor the reaction rates (Chopra et al. $1993 b)$.

xanthophyll carotenoids appeared to be more efficient antioxidants than $\beta$-carotene and active at ambient $\mathrm{O}_{2}$ pressures. Terao (1989) used zeaxanthin, astaxanthin and canthaxanthin which are relatively minor carotenoids in human blood. However, our own work principally on lutein (Fig. 2), but also lycopene and $\beta$-cryptoxanthin, suggests that these xanthophyll carotenoids are all better antioxidants than $\beta$-carotene in quenching lipid peroxy radicals and more efficient in vitro than $\alpha$-tocopherol (Chopra et al. 1993b).

The antioxidant mechanism of carotenoids contrast with that of $\alpha$-tocopherol. $\alpha$-Tocopherol donates an $\mathrm{H}$ atom to the lipid radical to produce a semi-stable lipid hydroperoxide and becomes a semiquinone radical. The latter is relatively stable and will stop the autocatalytic chain of lipid peroxidation, while it is reduced back to its active form. Its efficiency as an antioxidant depends, however, on being regenerated. If regeneration does not take place then its maximum peroxyl radical-quenching capacity will only be $2 \mathrm{~mol} \mathrm{O}_{2} / \mathrm{mol}$ tocopherol and it will then be irreversibly oxidized.

Smoking is one of the principal external sources of oxidative stress to which man is exposed and the habit is strongly associated with lung cancer. Some interesting relationships exist between smoking and blood carotene concentrations. Smoking is associated with a reduced intake of fruits and vegetables (Gregory et al. 1990) but also smokers have lower circulating levels of $\beta$-carotene than are found in non-smokers consuming the same level of dietary carotene (Fig. 3; Thurnham, 1990). In the British Adult survey, similar observations were made for lutein, $\beta$-cryptoxanthin and $\alpha$-carotene but not for lycopene (Thurnham \& Tyler, 1990). Smoking appears to have no influence on blood levels of lycopene in either men or women (Fig. 3) and similar findings have been reported both from Canada (Thompson et al. 1985) and America (Stryker et al. 1988). 

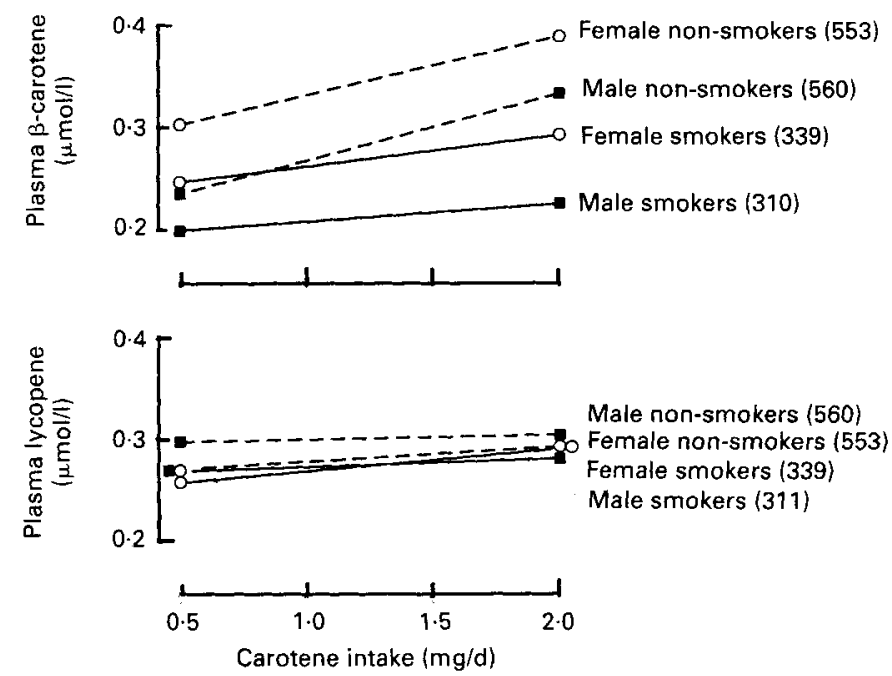

Fig. 3. Influence of smoking on plasma concentrations of $\beta$-carotene and lycopene in men and women in relation to dietary intake of $\beta$-carotene equivalents. The regression lines shown are obtained from data collected from adult British subjects who provided blood samples and $7 \mathrm{~d}$ weighed dietary intake data (Gregory et al. 1990). In the case of $\beta$-carotene the correlation coefficients for the non-transformed data were all significant $(P<0 \cdot 001)$. The significance of the differences between the slopes and elevations was calculated using logarithms base ten of carotene intakes by tests of parallelism. Within the sexes the difference between the slopes of the regression lines for smokers $(-)$ and non-smokers $(--)$ was significant for women $(O$; $P<0.005$ ) but not for men $(\boldsymbol{E})$, but the elevation of the plasma $\beta$-carotene regression line was significantly higher for non-smokers than for smokers (men $P<0.02$, women $P<0.001$ ). Analysis of the data on $\beta$-carotene by smoking habits between men and women showed that the slopes were different for non-smokers $(P<0 \cdot 01)$ but not for smokers and the elevations in both smokers $(P<0.005)$ and non-smokers $(P<0.001)$ were higher in the women than the men. In the case of lycopene, there were no significant differences in any of the comparisons mentioned (D. I. Thurnham and H. A. Tyler, unpublished results). Numbers in parentheses are the numbers of subjects in the respective groups.

\section{CAROTENOIDS AND IMMUNE FUNCTION}

This subject has been reviewed recently by Bendich (1991) and Krinsky (1991). There is both experimental and some human evidence of effects of various carotenoids on bacterial resistance, lymphocyte proliferation, T-helper cells, macrophage and natural killer cell cytotoxicity and readers should consult these two papers for further details.

\section{CONCLUSIONS}

Many carotenoids are present in nature but only a small number are found in appreciable quantities in the blood and tissues. These include $\alpha$ - and $\beta$-carotene, $\beta$-cryptoxanthin, lycopene, lutein and several other xanthophyll carotenoids which have not yet been identified. In the majority of tissues the distribution of these carotenoids is qualitatively similar to that found in the blood. The exceptions are the eye and HDL where xanthophyll carotenoids predominate.

$\beta$-Carotene is the major plant source of vitamin A and recent evidence would appear to confirm that excentric cleavage of the molecule is the major route of retinol formation. 
Singlet $\mathrm{O}$-scavenging properties of carotenoids are important in the plant, and the same mechanism may be responsible for the therapeutic usefulness of $\beta$-carotene in the treatment of erythropoietic protoporphyria. There is evidence to suggest that $\beta$-carotene $(30 \mathrm{mg} / \mathrm{d})$ may provide some protection against sunburn but $\beta$-carotene has not proven useful in protecting against non-melanomatous cancers in high-risk persons.

The long chain of conjugated double bonds is primarily responsible for the singlet $\mathrm{O}$ and peroxy radical-quenching properties of carotenoids but quantitative difference exists between the carotenoids. Several xanthophyll carotenoids are more efficient than $\beta$-carotene in scavenging peroxy radicals in vitro and lutein may be especially useful in protecting LDL from oxidation ex vivo.

There is evidence to suggest that carotenoids are important in preventing cardiovascular disease and some cancers. In particular lung and upper aerodigestive tract cancers appear to be influenced by carotenoids. Likewise, $\beta$-carotene supplements may reduce the risk of cardiovascular events particularly in those with previous problems. The precise mechanism(s) involved in these effects are not known but the main ones under investigation are antioxidant protection and influences on immune function.

The author thanks the Ministry of Agriculture, Fisheries and Food for permission to use unpublished material in Fig. 3.

\section{REFERENCES}

Bendich, A. (1991). B-Carotene and the immune response. Proceedings of the Nutrition Society 50, $263-274$.

Bieri, J. G., Brown, E. D. \& Smith, J. C. Jr (1985). Determination of individual carotenoids in human plasma by high performance chromatography. Journal of Liquid Chromatography 8, 473-484.

Burton, G. W. \& Ingold, K. U. (1984). $\beta$-carotene: an unusual type of lipid antioxidant. Science 224, 569-573.

Cantilena, L. R., Stukel, T. A., Greenberg, E. R., Nann, S. \& Nierenberg, D. W. (1992). Diurnal and seasonal variation of five carotenoids measured in human serum. American Journal of Clinical Nutrition $\mathbf{5 5}$, $659-663$.

Carew, T. E., Schwenke, D. C. \& Steinberg, D. (1987). Antiatherogenic effect of probucol unrelated to its hypocholesterolemic effect: Evidence that antioxidants in vivo can selectively inhibit low density lipoprotein degradation in macrophage-rich fatty streaks and slow the progression of atherosclerosis in the Watanabe heritable hyperlipidemic rabbit. Proceedings of the National Academy of Sciences, USA 84, 7725-7729.

Chopra, M., Puhl, H. \& Thurnham, D. I. (1993a). Effect of lutein on copper initiated oxidation of low density lipoproteins. Proceedings of the International Life Sciences Institute, Europe, p. 92 Abstr.

Chopra, M. \& Thurnham, D. I. (1994). Effect of lutein on oxidation of low-density lipoproteins (LDL) in vitro. Proceedings of the Nutrition Society 53, (In the Press).

Chopra, M., Willson. R. L. \& Thurnham, D. I. (1993b). Free radical scavenging activity of lutein in vitro. In Proceedings of the New York Academy of Sciences Conference, pp. 353-356 [L. M. Cranfield, J. A. Olson and N. I. Krinsky, editors]. New York: NY Academy of Sciences.

Connett, J. E., Kuller, L. H., Kjelsberg, M. O., Polk, B. F., Collins, G., Rider, A. \& Hulley, S. B. (1989) Relationship between carotenoids and cancer. The multiple risk factor intervention trial (MRFIT) study. Cancer 64, 126-134.

Cooney, R. V., Bertram, J. S., Hankin, J. H., Kolonel, L. N., Miyake, A., Billings, K. \& Bourne, W. (1991). Relationship between dietary, serum, and tissue levels of carotenoids. Cancer Letters 61, 81-87.

Culling-Berglund, A. J., Newcomb, S. A., Gagne, M., Morfitt, W. S. \& Davis, T. P. (1989). A sensitive and specific procedure for analysis of $\beta$-carotene in human skin. Journal of Micronutrient Analysis 5, 139-148.

Dieber-Rotheneder, M., Puhl, H., Waeg, G., Striegl, G. \& Esterbauer, H. (1991). Effect of oral supplementation with $\mathrm{D}$ - $\alpha$-tocopherol on the vitamin $\mathrm{E}$ content of human low density lipoprotein and resistance to oxidation. Journal of Lipid Research 32, 1325-1332.

Esterbauer, H., Dieber-Rotheneder, M., Striegl, G. \& Waeg, G. (1991). The role of vitamin E in preventing the oxidation of low-density lipoproteins. American Journal of Clinical Nutrition 53, 314S-321S. 
Esterbauer, H., Dieber-Rotheneder, M., Waeg, G., Striegl, G. \& Jurgens, G. (1990). Biochemical, structural and functional properties of oxidised low-density lipoprotein. Chemical Research in Toxicology 3, 77-92.

Foote, C. S. \& Denny, R. W. (1968). Chemistry of singlet oxygen. VII. Quenching by $\beta$-carotene. Journal of American Chemical Society 90, 6233-6235.

Garewal, H. \& Sharndas, G. J. (1991). Intervention trials with beta-carotene in precancerous conditions of the upper aerodigestive tract. In Micronutrients in Health and Disease, pp. 127-140 [A. Bendich and C. E. Butterworth, editors]. New York: Dekker.

Gaziano, J. M., Manson, J. E., Ridker, P. M., Buring, J. E. \& Hennekens, C. H. (1990). Beta carotene therapy for chronic stable angina. Circulation 82, Suppl. III, 201.

Gollnick, H., Hemmes, C., Tillmann, R., Chun, S. C., Sundermeir, K., Hopfenmuller, U. \& Biesalski, H. K. (1993). Beta-carotene supplementation and sun-induced alterations of the erythema response in human skin. Proceedings of the International Life Sciences Institute, Europe, pp. 88-89 Abstr.

Greenberg, E. R., Baron, J. A., Stukel, T. A., Stevens, M. M., Mandel, J. S., Spencer, S. K., Elias, P. M., Lowe, N., Nierenberg, D. W., Bayrd, G., Corwin Vance, J., Freeman, D. H. Jr, Clendenning, W. E., Kwan, T. \& Skin Cancer Prevention Group (1990). A clinical trial of beta carotene to prevent basal-cell and squamous-cell cancers of the skin. New England Journal of Medicine 323, 789-795.

Gregory, J., Foster, K., Tyler, H. \& Wiseman, M. (1990). The Dietary and Nutritional Survey of British Adults. London: H.M. Stationery Office.

Handelman, G. J., Dratz, E. A., Reay, C. C. \& Van Kuijk, J. G. M. (1988). Carotenoids in the human macula and whole retina. Investigative Ophthalmology \& Visual Science 29, 850-855.

Handelman, G. J., Snodderly, D. M., Krinsky, N. I., Russett, M. D. \& Adler, A. J. (1991), Biological control of primate macular pigment. Investigative Ophthalmology \& Visual Science 32, 257-267.

Hennekens, C. H. (1986). Micronutrients and cancer prevention. New England Journal of Medicine 315, $1288-1289$.

Horwitt, M. K., Harvey, C. C., Dahm, C. H. \& Searcy, M. T. (1972). Relationship between tocopherol and serum lipid levels for the determination of nutritional adequacy. Annals of the New York Academy of Sciences 203, 223-236.

Jialal, I. \& Grundy, S. M. (1991). Preservation of the endogenous antioxidants in low density lipoprotein by ascorbate but not probucol during oxidative modification. Journal of Clinical Investigation 87, 597-601.

Kaplan, L. A., Lau, J. M. \& Stein, E. A. (1990). Carotenoid composition, concentrations and relationships in various human organs. Clinical Physiology and Biochemistry 8, 1-10.

Krinsky, N. I. (1991). Effects of carotenoids in cellular and animal systems. American Journal of Clinical Nutrition 53, 238S-246S.

Krinsky, N. I., Cornwell, D. G. \& Oncley, J. L. (1958). The transport of vitamin A and carotenoids in human plasma 73, 233-246.

Lavy, A., Ben Amotz, A. \& Aviram, M. (1992). Preferential inhibition of LDL oxidation by the all-trans isomer of $\beta$-carotene in comparison with 9-cis $\beta$-carotene. European Journal of Clinical Chemistry and Clinical Biochemistry 31, 83-90.

Mathews-Roth, M. M. (1975). Presence of carotenoids in the erythrocyte membranes for carotenaemic and non-carotenaemic individuals. Clinical Chemistry 21, 258-259.

Mathews-Roth, M. M. (1978). Carotenoids in the leukocytes of carotenaemic and non-carotenaemic individuals. Clinical Chemistry 24, 700-701.

Mathews-Roth, M. M., Pathak, M. A., Fitzpatrick, T. B., Harber, L. C. \& Kass, E. H. (1977). Beta-carotene therapy for erythropoietic protoporphyria and other photosensitive diseases. Archives of Dermatology 113, 1229-1232.

Mathews-Roth, M. M., Wilson, T., Fujimore, E. \& Krinsky, N. I. (1974). Carotenoid chromophore length and protection against photosensitization. Photochemistry and Photobiology 19, 217-222.

Moon, R. C. (1989). Comparative aspects of carotenoids and retinoids as chemopreventive agents for cancer. Journal of Nutrition 119, 127-134.

Mordi, R. C. (1993). Carotenoids: functions and degradation. Chemistry and Industry issue 3, 79-83.

Morel, D. W., Hessler, J. R. \& Chisholm, G. M. (1983). Low density-lipoprotein cytotoxicity induced by free radical peroxidation of lipid. Journal of Lipid Research 24, 1070-1076.

Olson, J. A. (1989). Provitamin A function of carotenoids: the conversion of $\beta$-carotene into vitamin A. Journal of Nutrition 119, 105-108.

Parker, R. S. (1988). Carotenoid and tocopherol composition of human adipose tissue. American Journal of Clinical Nutrition 47, 33-36. 
Peto, R., Doll, R., Buckley, J. D. \& Sporn, M. B. (1981). Can dietary beta-carotene materially reduce human cancer rates? Nature 290, 201-208.

Princen, H. M. G., Van Poppel, G., Vogelezang, C., Buytenhek, R. \& Kok, F. J. (1992). Supplementation with vitamin $E$ but not $\beta$-carotene in vivo protects low density lipoprotein from lipid peroxidation in vitro. Effect of cigarette smoking. Arteriosclerosis and Thrombosis 12, 554-562.

Regnstrom, J., Nilsson, J., Tornvall, P., Landou, C. \& Hamsten, A. (1992). Susceptibility to low-density lipoprotein oxidation and coronary atherosclerosis in man. Lancet 339, 1183-1186.

Schmitz, H. H., Poor, C. L., Wellman, R. B. \& Erdman, J. W. Jr (1991). Concentrations of selected carotenoids and vitamin A in human liver, kidney and lung tissue. Journal of Nutrition 121, 1613-1621.

Stich, H. F., Rosin, M. P., Hornby, A. P., Mathew, B., Sankaranarayanan, R. \& Krishnan Nair, M. (1988). Remission of oral leukoplakias and micronuclei in tobacco/betel quid chewers treated with beta-carotene and with beta-carotene plus vitamin A. International Journal of Cancer 42, 195-199.

Stich, H. F., Stich, W., Rosin, M. P. \& Vallejera, M. O. (1984). Use of the micronucleus test to monitor the effect of vitamin $\mathrm{A}$, beta-carotene and canthaxanthin on the buccal mucosa of betel nut/tobacco chewers. International Journal of Cancer 34, 745-750.

Stryker, W. S., Kaplan, L. A., Stein, E. A., Stampfer, M. J., Sober, A. \& Willett, W. C. (1988). The relation of diet, cigarette smoking, and alcohol consumption to plasma beta-carotene and alpha-tocopherol levels. American Journal of Epidemiology 127, 283-296.

Terao, J. (1989). Antioxidant activity of $\beta$-carotene-related carotenoids in solution. Lipids 24, 659-661.

Thompson, J. N., Duval, S. \& Verdier, P. (1985). Investigation of carotenoids in human blood using high-performance liquid chromatography. Journal of Micronutrient Analysis 1, 81-91.

Thurnham, D. I. (1989). Lutein, cholesterol, and risk of cancer. Lancet ii, 441-442.

Thurnham, D. I. (1990). Anti-oxidant vitamins and cancer prevention. Journal of Micronutrient Analysis 7 , 279-299.

Thurnham, D. I. (1993). Chemical aspects and biological mechanisms of anti-cancer nutrients in plant foods. In Food and Cancer Prevention, pp. 109-118 [K. W. Waldron, I. T. Johnson and G. R. Fenwick, editors]. London: Royal Society of Chemistry.

Thurnham, D. I., Chopra, M. \& Leake. D. (1993). A role for lutein in influencing oxidation of low density lipoprotein. Irish Journal of Medical Science (In the Press).

Thurnham, D. I. \& Flora, P. S. (1988). Do higher vitamin A requirements in men explain the difference between the sexes in plasma provitamin A carotenoids and retinol. Proceedings of the Nutrition Society $\mathbf{4 7}$, $181 \mathrm{~A}$.

Thurnham, D. I. \& Tyler, H. A. (1990). Factors influencing plasma carotenoids in British adults. Ninth International Symposium on Carotenoids A6-2, p. 27 Abstr.

van Hinsbergh, V. W., Scheffer, M., Havekas, L. \& Kempen, H. J. (1986). Role of endothelial cells and their products in the modification of low density lipoprotein. Biochimica et Biophysica Acta 878, 49-64.

Wang, X.-D., Tang, G.-W., Fox, J. G., Krinsky, N. I. \& Russell, R. M. (1991). Enzymic conversion of $\beta$-carotene in $\beta$-apocarotenals and retinoids by human, monkey, ferret, and rat tissues. Archives of Biochemistry and Biophysics 285, 8-16.

Winklhofer-Roob, B. M., Puhl, H., Schmerling, D. H. \& Esterbauer, H. (1993). Improved oxidation resistance of low-density lipoproteins of cystic fibrosis patients after efficient beta-carotene supplementation. Proceedings of the International Life Sciences Institute, Europe, p. 116 Abstr. 